\title{
Zooplankton in a marine bay. II. Vertical migration to maintain horizontal distributions
}

\author{
W. J. Kimmerer*, A. D. McKinnon** \\ Department of Zoology, University of Melbourne, Parkville, Victoria 3052, Australia
}

\begin{abstract}
Zooplankton populations can maintain their horizontal distributions by the interaction of vertical movement with current shear. In Westernport Bay, Australia, a poorly stratified marine bay, current shear results from bottom friction, and its direction changes with that of the tidal stream. Vertical profiles of zooplankton abundance showed that adults of the most abundant species resident in the bay, Acartia tranteri (medium sized form), migrate vertically in synchrony with the tides, and in a direction to reduce losses to mixing out of the bay. We develop a simple model to show that this vertical migration of A. tranteri adults was sufficient on average to overcome mixing losses. Pseudodiaptomus cornutus may have also migrated vertically to avoid mixing out of the bay, but other bay residents did not; these species may have alternative strategies to mitigate against washout. None of the non-resident species migrated in synchrony with the tides, presumably because of a lack of selective pressure to do so.
\end{abstract}

\section{INTRODUCTION}

Plankton populations often vary their horizontal distributions by adjusting vertical position in the presence of current shear. The mechanism of yertical positioning may be passive: preference for a certain depth may result in a distinct horizontal pattern, such as in the concentration of buoyant or upwardly-swimming plankters by wind-driven currents (Seliger et al. 1970), eddies (Alldredge \& Hamner 1980), or Langmuir circulation (Stavn 1971); organisms avoiding the surface may become concentrated in the channels of bays or estuaries (Jacobs 1968); and neutrally buoyant particles including plankton can be concentrated by the 2layer flow of stratified estuaries (Pritchard \& Schubel 1981). Zooplankton can also actively use current shear to maintain horizontal position in vertically stratified estuaries having reversed flow at depth (Bosch \& Taylor 1973, Orsi 1986), and in coastal upwelling regions (Peterson et al. 1979). Active migration is better known from studies of demersal organisms such as plaice (Greer Walker et al. 1978) or meroplanktonic decapod larvae (Young \& Carpenter 1977, Cronin \& Forward 1979, Cronin 1982), which can use tidal or estuarine currents for horizontal transport.

- Present address: BioSystems Analysis, Inc, Bldg 1065, Ft. Cronkhite, Sausalito, California 94965, USA

- Present address: Australian Institute of Marine Science, PMB No. 3, Townsville, Queensland, Australia
In poorly stratified bays, currents are tidal and unidirectional at all depths except near slack water. Current shear still exists because of bottom friction, and some zooplankton may be able to maintain position by migrating vertically across this shear (Wooldridge \& Erasmus 1980, Cronin 1982).

In this paper we test the hypothesis that zooplankton migrate vertically in response to tidal direction in the western entrance channel of Westernport Bay, Australia. We devise a simple model of the plankton flux resulting from the interaction of vertical distributions of plankton abundance and current velocity, and use it to determine whether the observed migration was sufficient to maintain observed horizontal gradients in abundance.

\section{METHODS}

Westernport Bay (Fig. 1, p. 44, in Kimmerer \& McKinnon 1987a [preceding article]) has a wide western entrance and a narrow eastern entrance. Since most of the exchange occurs through the western entrance (Harris \& Robinson 1979), we consider that entrance only. It is about $8 \mathrm{~km}$ wide, shoaling from $20 \mathrm{~m}$ depth at the mouth to $3 \mathrm{~m}$ at the landward end. A channel about $2.5 \mathrm{~km}$ wide and 20 to $30 \mathrm{~m}$ deep has tidal currents that average $0.33 \mathrm{~m} \mathrm{~s}^{-1}$ (Hinwood \& Jones 1979) but can be much stronger. Turbulence in 
Table 1. Sampling conditions and numbers of samples collected

\begin{tabular}{|c|c|c|c|c|}
\hline Sample set & $\begin{array}{l}\text { Predicted } \\
\text { slack water } \\
\text { times (h) }\end{array}$ & $\begin{array}{l}\text { Tidal } \\
\text { range } \\
(\mathrm{m})\end{array}$ & $\begin{array}{c}\text { Weather } \\
\text { con- } \\
\text { ditions }\end{array}$ & $\begin{array}{c}\text { No. } \\
\text { of } \\
\text { samples }\end{array}$ \\
\hline Set 1 , day 1 & $\begin{array}{l}\text { L } 1150 \\
\text { H } 1820\end{array}$ & 2.1 & $\begin{array}{l}\text { Overcast } \\
\text { Wind SW } \\
5-15 \mathrm{kn}\end{array}$ & 16 \\
\hline Set 1 , night 1 & $\begin{array}{l}\text { L } 0010 \\
\text { H } 0630\end{array}$ & 2.1 & $\begin{array}{l}\text { Overcast } \\
\text { Wind SW } \\
10-15 \mathrm{kn}\end{array}$ & 16 \\
\hline Set 1 , day 2 & $\begin{array}{l}\text { L } 1220 \\
\text { H } 1900\end{array}$ & 2.0 & $\begin{array}{l}\text { Overcast } \\
\text { Wind SW } \\
10-15 \mathrm{kn}\end{array}$ & 16 \\
\hline Set 2 & L 1325 & 1.7 & $\begin{array}{c}\text { Clear, hazy } \\
\text { Wind NW } \\
5-10 \mathrm{kn}\end{array}$ & 34 \\
\hline Set 3 & H 1300 & 2.0 & $\begin{array}{c}\text { Mostly over- } \\
\text { cast } \\
\text { Wind SW } \\
5-10 \mathrm{kn}\end{array}$ & 16 \\
\hline
\end{tabular}

the tidal channels of Westernport Bay is sufficient to prevent stratification and to keep a considerable load of particulate matter, sometimes including sand, in suspension. Current velocities vary logarithmically with depth (Hinwood \& Jones 1979, Osonphasop 1983, Hinwood pers. comm.).

Vertical profiles of zooplankton abundance in the western entrance channel were determined on 3 occasions. Table 1 gives conditions of tide and weather, and numbers of samples collected, for each sample set. On 25 and 26 Feb 1985 (Set 1) samples were collected with $190 \mu \mathrm{m}$ mesh, $30 \mathrm{~cm}$ diameter Clarke-Bumpus nets near Stn E (Kimmerer \& McKinnon 1987a). Each profile consisted of 4 samples taken in random sequence: a surface sample, a near-bottom sample, and 2 intermediate samples. Duplicate profiles were taken during 6 consecutive runs of the tide. On $11 \mathrm{Jul} 1985$ (Set 2) and 1 Aug 1985 (Set 3) we took pump samples from 1 to $2 \mathrm{~m}$ depth and from within $2 \mathrm{~m}$ of the bottom, while following a $4 \mathrm{~m}$ parachute drogue set at $5 \mathrm{~m}$ depth. The pump discharge was passed through a $200 \mu \mathrm{m}$ mesh net for about $8 \mathrm{~min}$ to collect each sample; the volume filtered, determined by timing the filling of a bucket, was about $0.8 \mathrm{~m}^{3}$. Samples were taken alternately from the 2 depths as rapidly as possible.

In Sample Set 2 the drogue moved $10.7 \mathrm{~km}$ seaward from the release point near Stn F (Fig. 1 in Kimmerer \& McKinnon 1987a), returning on the flood ticle to near Stn F by the end of the sampling period. In Sample Set 3 the drogue moved in from Stn E almost to Stn G, a distance of about $7 \mathrm{~km}$, and back. Maximum current velocities were about $1.2 \mathrm{~m} \mathrm{~s}^{-1}$ on each date.

All samples were preserved in 2 to $4 \%$ formal- dehyde. In Sample Set 1 we identified and counted all taxa in aliquots taken with a plankton splitter. We analyzed whole samples from Sample Sets 2 and 3 but counted only adults of the most common taxa, the copepods Acartia tranteri and Paracalanus indicus. Acartia tranteri has 3 distinct size classes: a large form and rarely a small form are resident in Bass Strait, adjacent to Westernport Bay, and a medium form is the numerical dominant within the bay (Kimmerer \& McKinnon 1985, McKinnon unpubl. data). These may be separate species, and were therefore treated separately. We refer to these size classes by appending $\mathrm{S}$ (small), M (medium), or L (large) to the species name. These size classes overlap except in the adult female, but males can be distinguished by color if they are examined soon after collection. We determined proportions of females in each size class and used these proportions to estimate the abundances of males and juveniles in each size class for Sample Set 1. For Sample Sets 2 and 3 we determined size classes of all adults counted.

The hypothesis that vertical distribution changes with direction of tidal flow was tested for Sample Set 1 by analysis of variance of the mean depths (centers of mass) obtained in each profile. The depths were rescaled to a total water column depth of $30 \mathrm{~m}$ to eliminate bias caused by tidal variation in actual water column depth (Cronin 1982). In Sample Sets 2 and 3 an analysis of variance of log-transformed abundance was used to test the hypothesis that the ratio of surface to bottom abundance changed with direction of the tidal stream; in this case the test of interest was for the depth-tide interaction term. In both cases preliminary tests indicated no significant heterogeneity of variance, except where noted.

Plankton flux model. Although the tests described above showed significant tidally-oriented vertical migration for adults of one species, they do not indicate whether the migration was large enough to offset mixing due to gradients in abundance along the channel. We therefore constructed a simple model to estimate the magnitude of the horizontal flux resulting from the vertical migration, and compared this approximate flux with that due to mixing.

If zooplankton can swim up or down in response to the tidal currents, their vertical distribution will vary with tidal direction. The interaction of vertical distribution with depth-varying current velocity will produce a net horizontal flux of animals. To determine this flux analytically we made the following assumptions: (1) zooplankton swim vertically at a constant speed in one direction on the flood tide, the other on the ebb; (2) the resulting steady-state vertical distributions (see below) change instantaneously with reversal of the tide; (3) a rectilinear tidal current is used, i. e. the tide flows at 
Table 2. Symbols used in the model with meanings

\begin{tabular}{|c|c|}
\hline Symbol & Meaning \\
\hline$Q_{z}$ & Concentration of a zooplankton species at depth $z$ \\
\hline$Q_{1}$ & $\begin{array}{l}\text { Depth-averaged concentration of a species in Sec- } \\
\text { tor } 1\end{array}$ \\
\hline w & Swimming velocity, positive downward \\
\hline$\omega$ & Dimensionless swimming velocity \\
\hline$\varepsilon$ & Coefficient of vertical eddy diffusivity \\
\hline D & Water column depth \\
\hline$z_{0}$ & Channel roughness height \\
\hline $\mathrm{d}$ & Dimensionless channel depth \\
\hline $\mathrm{U}_{2}$ & Current velocity at depth $z$ (positive for flood) \\
\hline W & Channel width \\
\hline $\mathrm{T}$ & Tidal period \\
\hline $\mathrm{z}_{\mathrm{T}}$ & Tidal range \\
\hline $\mathrm{z}_{2}$ & Mean depth of Sector 2, the upper bay \\
\hline$x_{12}$ & Exchange coefficient between Sectors 1 and 2 \\
\hline $\mathrm{F}$ & $\begin{array}{l}\text { Migratory flux of zooplankton through channel } \\
\text { cross-section }\end{array}$ \\
\hline f & Dimensionless efficiency of migratory flux \\
\hline$\Phi$ & Flux of zooplankton due to mixing along channel \\
\hline $\mathrm{Y}$ & Ratio of migratory to mixing fluxes of zooplankton \\
\hline$Y^{\prime}$ & Factor used to calculate $Y$ from abundance data \\
\hline $\mathrm{S}$ & Slope of log abundance vs depth \\
\hline
\end{tabular}

constant velocity during each half tidal period; and (4) the coefficient of vertical eddy diffusivity is assumed to be invariant with depth, and vertical diffusion can be modeled as a Fickian process. Violations of these assumptions are considered further in the 'Discussion'. Symbols used in the model are defined in Table 2.

Under the above assumptions a steady state distribution of zooplankton develops in which directed swimming by the animals is offset by mixing along the vertical gradient of abundance. The vertical distribution of zooplankton can be determined from a transport equation:

$$
\frac{\partial Q_{z}}{\partial t}=0=-w \frac{\partial Q_{z}}{\partial z}+\varepsilon \frac{\partial^{2} Q_{z}}{\partial z_{2}}
$$

The solution is

$$
\mathrm{Q}_{\mathrm{z}}=\mathrm{Q}_{0} \mathrm{e}^{\mathrm{wz} / \varepsilon}
$$

where $Q_{0}=$ the surface concentration. The relation of abundance at depth $\mathrm{z}$ to mean abundance $\overline{\mathrm{Q}}$ is

$$
Q_{z}=\bar{Q} \frac{\omega e^{w z / D}}{\left(e^{\omega}-1\right)}
$$

where $\omega=w D / \varepsilon$ is a dimensionless swimming velocity. The mean depth or center of mass of the distribution is then

$$
\overline{\mathrm{z}}=\mathrm{D} \frac{1}{\left(1-\mathrm{e}^{-\omega}\right)}-\frac{1}{\omega}
$$

Numerous vertical profiles of tidal current velocity in Westernport Bay channel (Hinwood \& Jones 1979 ,
Osonphasop 1983, Hinwood pers. comm.) show velocity to be logarithmically distributed with depth:

$$
\mathrm{U}_{\mathrm{z}} \propto \ln \left(\frac{\mathrm{D}-\mathrm{z}}{\mathrm{z}_{0}}\right)
$$

where the roughness height $\mathrm{z}_{0}$ has values of 0.01 to 0.3 m (Hinwood \& Jones 1979, Osonphasop \& Hinwood 1984). The relation of velocity at depth $\mathrm{z}$ to depthaveraged velocity $\bar{U}$ is:

$$
U_{z}=\bar{U} \frac{\ln \left(\frac{D-z}{z_{0}}\right)}{\ln \left(D / z_{0}\right)-1}
$$

The horizontal flux of animals during a half tide through a cross section of the channel is

$$
\mathrm{F}=\mathrm{W} \int_{0}^{\mathrm{T} / 2} \int_{0}^{\mathrm{D}} \mathrm{Q}_{\mathrm{z}} \mathrm{U}_{\mathrm{z}} \mathrm{dzdt}
$$

Now let $f$ be the dimensionless efficiency of tidal transport during each tide,

$$
\mathrm{f}=\frac{\mathrm{F}}{\mathrm{V}_{\mathrm{T}} \overline{\mathrm{Q}}}=\frac{2 \mathrm{~F}}{\mathrm{TWD} \overline{\mathrm{U}} \overline{\mathrm{Q}}}
$$

where $V_{\mathrm{T}}=$ volume of the tidal prism, equal to the cross-sectional area times the mean velocity of the tidal flow times the tidal period. Inserting Eq. (7) into Eq. (8) and replacing $Q_{z}$ und $U_{z}$ with the expressions in Eqs. (3) and (6) gives

$$
f=\frac{\omega}{D\left(e^{\omega}-1\right)\left(\ln \left[D / z_{0}\right]-1\right)} \int_{0}^{D} \ln \left(\frac{D-z}{z_{0}}\right) e^{w z / D} d z(9)
$$

Integrating over the depth gives

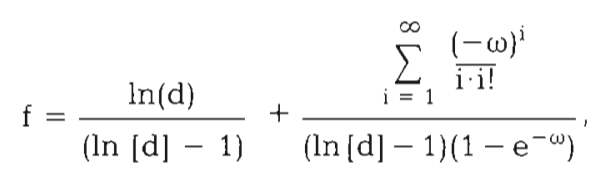

a function of the dimensionless variables $\omega$ and $d$. Over an entire day the net flux of animals is

$$
2 \mathrm{~T}\left(\mathrm{~F}^{+}-\mathrm{F}^{-}\right)=2 \mathrm{~V}_{\mathrm{T}} \mathrm{Q}\left(\mathrm{f}^{+}-\mathrm{f}^{-}\right)
$$

where the superscripts + and - refer to flood and ebb tidal currents respectively. A positive value means a net flux into the bay. The flux of animals due to mixing in the opposite direction would be

$$
\Phi=\left(Q_{2}-Q_{1}\right) x_{12} V_{2}
$$

where $Q_{1}$ and $Q_{2}$ refer to concentrations of animals in the western entrance and upper bay, respectively (see box model; Kimmerer \& McKinnon 1987a). Assuming 
that $Q=\left(Q_{1}+Q_{2}\right) / 2$, the ratio of vertical migration flux from Eq. (11) to mixing flux from Eq. (12) is

$$
Y=Y^{\prime} \frac{Q_{1}+Q_{2}}{Q_{2}-Q_{1}}, \quad Y^{\prime}=\frac{z_{\Upsilon}\left(f^{+}-f^{-}\right)}{z_{2} x_{12}}
$$

Note that a flux ratio $Y$ of 1 implies that vertical migration flux is equal and opposite to the mixing flux.

The model was used to determine whether values of $Y$ determined from field data were as large as 1 . The dimensionless swimming velocity $\omega$ was determined for each tide from the vertical distribution data. Note that in Sample Set 1 , the average correlation $\left(\mathrm{r}^{2}\right)$ for the fit of individual profiles to an exponential curve was 0.42 . From Eq. (2), the slope of log abundance vs depth is

$$
\mathrm{S}=\frac{\mathrm{w}}{\varepsilon}=\frac{\omega}{\bar{D}}, \text { or } \omega=\mathrm{SD}
$$

Preliminary analysis revealed that the model was insensitive to values of $z_{0}$, used in calculating the dimensionless depth $d$, within the range of 0.01 to 0.3 ; a constant value of $d$ of 2000 was therefore used throughout. The mean depth of the upper bay is about $6.5 \mathrm{~m}$, the tidal range $2.2 \mathrm{~m}$, and the exchange coefficient $0.016 \mathrm{~d}^{-1}$ between the western entrance and the entire upper bay (Sectors 2 and 3 combined; Kimmerer \& McKinnon 1987a). Values of the flux factor $Y^{\prime}$ were determined from mean values of $\omega$, and $Y$ was calculated using values of abundance $Q_{1}$ and $Q_{2}$ taken in a series of transects up the bay (Kimmerer \& McKinnon 1987 a)

Swimming speeds necessary to sustain the observed vertical distributions were calculated from the values of $\omega$. The coefficient of eddy diffusivity was estimated as:

$$
\varepsilon \approx \sigma_{\mathrm{v}} \ell
$$

where $\sigma_{v}=$ variance of vertical velocity, equal to about $0.05 \overline{\mathrm{U}}$ for Westernport Bay (Osonphasop \& Hinwood 1984); and $\ell=$ a characteristic length scale for the largest eddies, taken here to be $0.6 \mathrm{D}$. U averages 0.33 m $\mathrm{s}^{-1}$ (Hinwood \& Jones 1979). Thus the swimming speed is

$$
w=\frac{\omega \varepsilon}{D}=0.01 \omega
$$

\section{RESULTS}

Centers of mass of several common taxa in Sample Set 1 (Fig. 1) show relatively little effect of tidal direction except for adults of Acartia tranteri (M). The mean depth of this copepod was on average $3 \mathrm{~m}$ less on the flood tide than on the ebb (2-way ANOVA, $F_{1,8}=20.8$, $\mathrm{p}=0.004)$. Of the other common taxa, Pseudodiaptomus cornutus adults showed a marginally insignificant tidal effect $\left(F_{1,8}=5.81, p=0.053\right)$. No other taxon

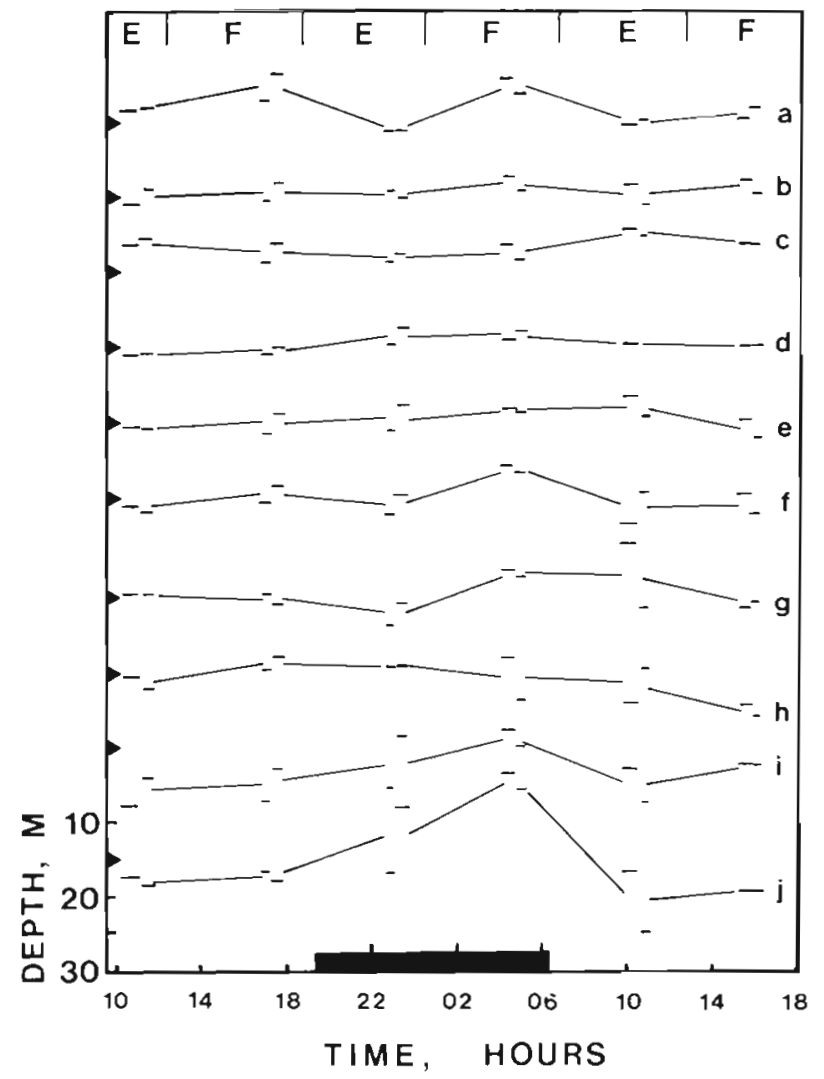

Fig. 1. Sample Set 1. Mean depth (center of mass) of common taxa plotted over time. $Y$ axis scale applies to all taxa, but all except (j) are shifted upward for legibility. Solid triangles at left indicate $15 \mathrm{~m}$ depth for each taxon. Short horizontal lines indicate duration of sampling periods. Solid lines connect pairs of profiles for readability, but do not indicate expected trajectory of the populations between sampling periods. At top: F, flood tide; E, ebb. At bottom: dark bar, period of darkness. (a) Acartia tranteri (M) adults; (b) A. tranteri (L) adults; (c) A. tranteri copepodites; (d) Paracalanus indicus adults; (e) P. indicus copepodites; (f) Pseudodiaptomus cornutus adults; (g) $P$. cornutus copepodites; (h) Bestiola similis

adults; (i) Meganyctiphanes australis; (j) Sagitta guileri

varied vertically with tide, although Paracalanus indicus adults and Sagitta guileri showed an apparent diel pattern. This was significant for $P$. indicus $\left(F_{1,7}=9.02\right.$, $p=0.0014)_{i}$ for $S$. guileri the test was significant $\left(F_{1,7}=\right.$ 25.8, $p<0.001$ ); but variances were heterogeneous because this chaetognath was not abundant in 1 of the 4 surface samples taken at night.

No other taxa showed any tidal or diel vertical migration. These included the bay resident species Bestiola similis as well as several non-resident species and unidentified crab zoeae.

The bay resident species Acartia tranteri (M), Pseudodiaptomus comutus, and Sagitta guileri were generally more abundant on the ebb tide, and Bass Strait residents $A$. tranteri (L), Paracalanus indicus, and 

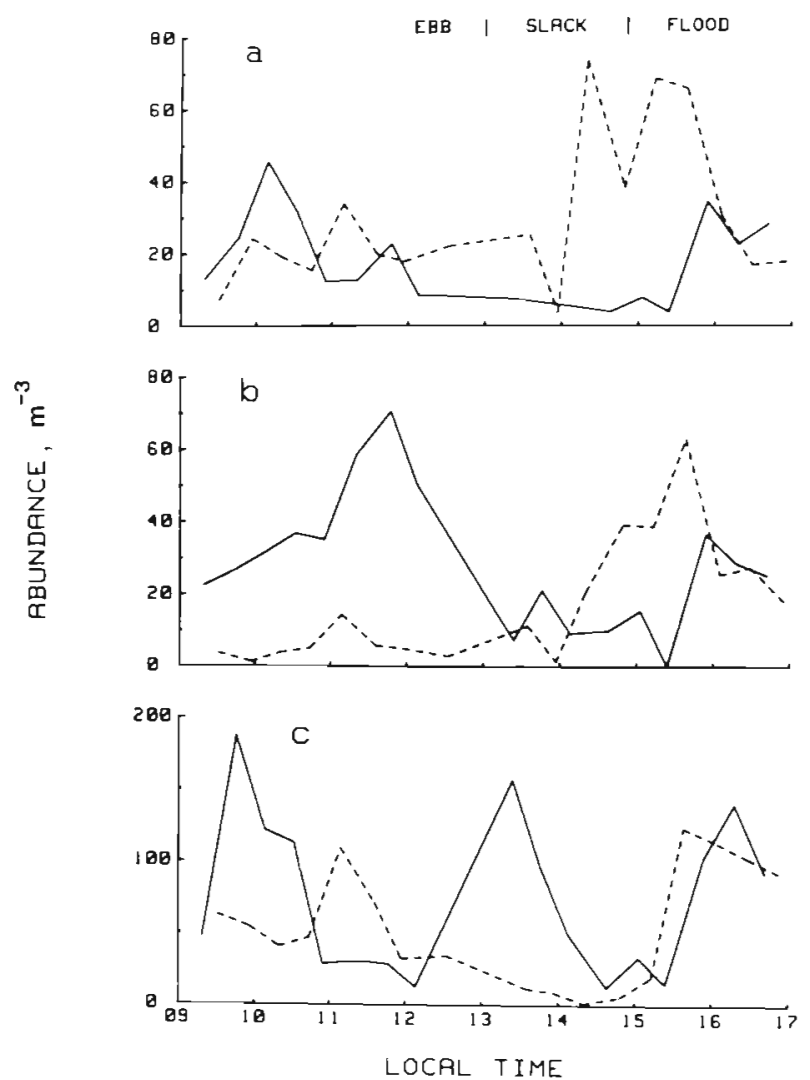

Fig. 2. Sample Set 2. Abundances of adult copepods (ind $\mathrm{m}^{-3}$ ) in bottom (solid) and surface (dashed) samples. (a) Acartia tranteri (L) adults; (b) A. tranteri (M) adults; (c) Paracalanus indicus adults

euphausiids (mostly Meganyctiphanes australis calyptopes and furcilia) less abundant, than on the flood tide. This is probably due to timing of the samples, which were taken toward the end of each tide. Mean depths of most taxa including $A$. tranteri (M) varied similarly between replicate profiles, probably because of variations in volume filtered. Variation between mean depths on replicate profiles was greatest for the less common taxa.

In Sample Sets 2 and 3, the only common taxa were Acartia tranteri $(\mathrm{M})$ and $(\mathrm{L})$ and Paracalanus indicus. Of these, only $A$. tranteri (M) showed a clear effect of tide on depth distributions (Fig. 2 \& 3). This copepod was more abundant at the bottom than the surface on the ebb, and usually less abundant at the bottom on the flood. The other 2 copepods showed irregular patterns. Although $A$. tranteri (L) was more abundant at the surface than near the bottom on the early part of the flood in Sample Set 2, it was more abundant at the surface on the ebb in Sample Set 3. Paracalanus indicus left the surface during slack water (Sample Set 2), but while the tide was running did not appear to control its position.

Two-way ANOVA confirmed the tidal effects noted
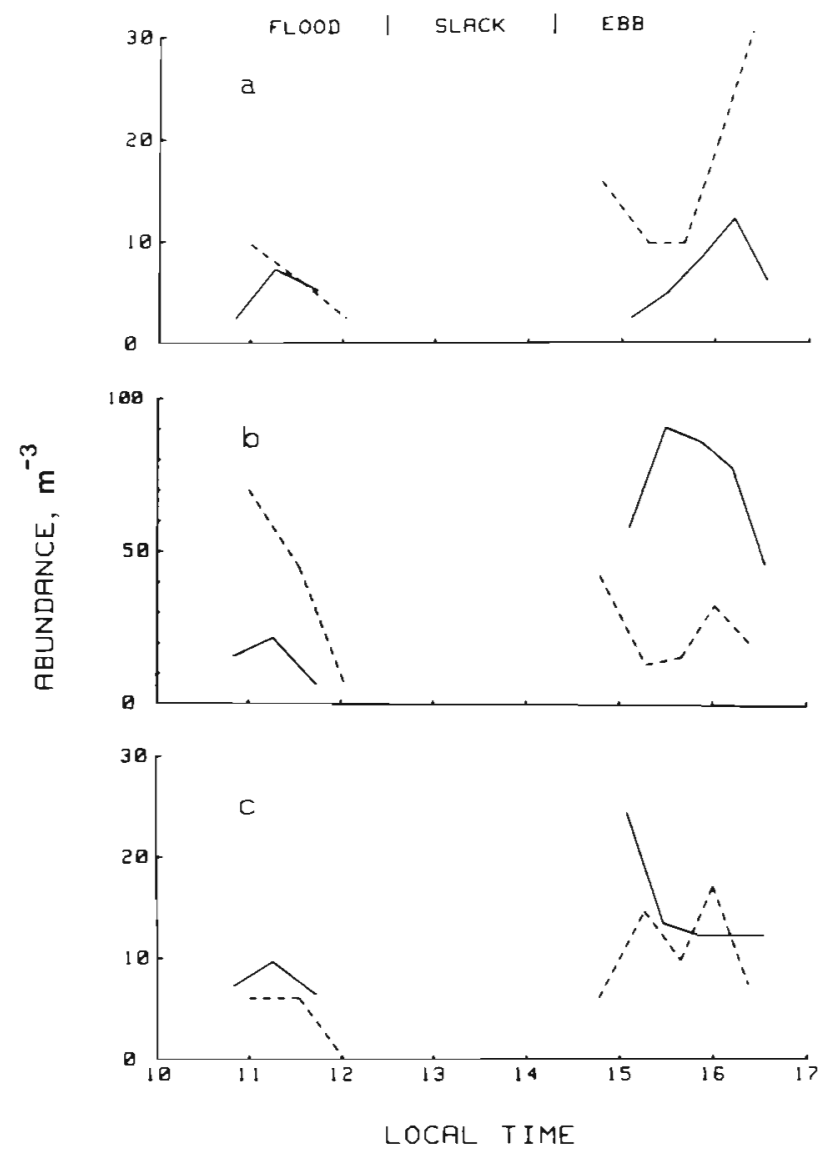

Fig. 3. Sample Set 3. As in Fig. 2

above: log-transformed abundance of Acartia tranteri (M) showed a significant depth-tide interaction in both Sample Sets $2\left(F_{1,21}=33.8, p=0.00001\right)$ and $3\left(F_{1,12}=\right.$ $8.54, p=0.013$ ). Note that 1 outlier was removed from Sample Set 2 to make the variances homogeneous; this was a bottom sample that contained a total of only 12 animals, and we suspect that the pump intake may have been blocked. Neither A. tranteri (L) nor Paracalanus indicus had a significant depth-tide interaction $(p>0.1)$.

Values of the dimensionless swimming speed $\omega$, as calculated from all abundance data using Eq. (14), are shown in Table 3 for Acartia tranteri (M). Although individual values are highly variable, all show the same trend: negative (i.e. swimming up) on the flood tide, and either positive or less negative on the ebb. Mean swimming velocities were $-0.009 \mathrm{~m} \mathrm{~s}^{-1}$ on the flood and $+0.007 \mathrm{~m} \mathrm{~s}^{-1}$ on the ebb, with an overall mean swimming speed of $0.009 \mathrm{~m} \mathrm{~s}^{-1}$. The flux factor $Y^{\prime}$, calculated from the swimming velocities, was always positive, and greater than 1 for 3 of the 5 sample sets. The mean value of $Y^{\prime}$ based on all data combined was 1.18 , significantly different from $0(\mathrm{t}=3.73, \mathrm{p}<0.05$, $4 \mathrm{df})$. 
Table 3. Acartia tranteri (M). Results of model calculations. Dimensionless swimming speed (mean \pm range for Set 1 , mean $\pm 95 \%$ $\mathrm{CL}$ for Sets 2 and 3) for flood tide $\left(\omega^{+}\right)$and ebb tide $\left(\omega^{-}\right)$; flux factor $Y^{\prime}$; and swimming velocities ( $w$, ms ${ }^{-1}$ ) necessary to maintain observed distributions

\begin{tabular}{lccccc}
\hline Sample set & $\begin{array}{c}\text { Flood } \\
\omega^{+}\end{array}$ & $\begin{array}{c}\text { Ebb } \\
\omega^{-}\end{array}$ & $\mathrm{Y}^{\prime}$ & $\mathrm{w}^{+}$ \\
\hline Set 1, day 1 & $-1.27 \pm 0.70$ & $-0.44 \pm 0.01$ & 0.58 & -0.013 & -0.004 \\
Set 1, night 1 & $-1.96 \pm 0.01$ & $0.35 \pm 0.01$ & 1.62 & -0.020 & 0.004 \\
Set 1, day 2 & $-0.25 \pm 0.21$ & $0.10 \pm 0.19$ & 0.28 & -0.002 & 0.001 \\
Set 2 & $-0.04 \pm 0.84$ & $2.23 \pm 0.59$ & 1.91 & -0.0004 & 0.022 \\
Set 3 & $-0.78 \pm 1.70$ & $1.12 \pm 0.83$ & 1.53 & -0.008 & 0.011 \\
\hline
\end{tabular}

\section{DISCUSSION}

Tests of tidal effect on vertical position of adults of Acartia tranteri (M) were significant for all 3 sample sets and consistent with vertical migration in response to tidal direction in the western entrance of Westernport Bay. The observed variation in vertical position cannot be attributed to differential advection of copepods at different depths: on the ebb tide, advection at the surface would be faster than at depth, so at any point the surface water would have traveled further and should contain a greater abundance of bay resident copepods than the deep water. The migration detected is in a direction to maintain the population in the bay, thereby reducing or eliminating washout.

This is not the first report of tidally oriented vertical migration by Acartia species. Trinast (1975) reported that $A$. californiensis congregated in the depths of Newport Bay during the ebb tide over a single $24 \mathrm{~h}$ period. The data presented (her Fig. 4) show this preference for deep water, but the evidence for upward movement is equivocal, and no statistical tests were presented. Wooldridge \& Erasmus (1980) described tidally oriented vertical migration during one night's sampling in the Sundays River estuary (South Africa), a shallow $(4 \mathrm{~m})$, well-mixed estuary with a short residence time. Acartia natalensis migrated vertically to maintain its upstream position, while A. longipatella remained near the bottom on both tides.

Several other planktonic taxa have been shown to migrate in synchrony with tides to maintain or change position. This is best known for decapod larvae (Young \& Carpenter 1977, Cronin \& Forward 1979, Cronin 1982, Rothlisberg et al. 1983). Mysids also migrate vertically in apparent response to the tide (Wooldridge \& Erasmus 1980, Orsi 1986). In all of the cases cited here, tidallyoriented migration was in a direction to maintain populations within a bay, or to move shoreward.

Vertical migration in response to changes in light level is probably ubiquitous among epipelagic marine zooplankton, and is known to occur in species of Acartia (Landry 1978). The occurrence of vertical migration of Acartia in response to direction of tidal flow in both a shallow estuary with a short residence time (Wooldridge \& Erasmus 1980) and a deeper marine bay with a residence time of 2 mo (this report) suggests that this form of migration may also be widespread among Acartia species in tidal bays.

The orienting mechanism for tidally oriented migration may be difficult to identify. The animals could presumably detect turbulence or changes in turbidity associated with the strength of the tidal flow (Cronin \& Forward 1979, Sulkin 1984). They might have established an endogenous rhythm, swimming up on one tide and down on the next (Cronin \& Forward 1979), but it is difficult to imagine a mechanism by which planktonic copepods could detect the direction of flow, thereby setting their rhythm to the correct phase.

The mean swimming speed of Acartia tranteri (M), determined from the values for $\omega$ using Eq. (16), was about $30 \mathrm{~m} \mathrm{~h}^{-1}$. Most of the data on swimming speeds of copepods are laboratory data based on relatively short bursts of swimming (e.g. Hardy \& Bainbridge 1954), and longer-term laboratory experiments may not introduce sufficient motivation for sustained rapid swimming (Enright 1977). A study of vertical migration by the copepod Metridia pacifica revealed steady swimming speeds averaging $55 \mathrm{~m} \mathrm{~h}^{-1}$ (Enright 1977). This copepod is about $2.5 \mathrm{~mm}$ long, or about 3 times the length of $A$. tranteri (M). Swimming speeds should be proportional to length, so the swimming speed determined for $A$. tranter $(M)$ is high. Eq. (15) is only a rough approximation of the eddy diffusivity, so $30 \mathrm{~m} \mathrm{~h}^{-1}$ could be an overestimate. Also, mixing is not really the Fickian process modeled here. It is conceivable that copepods could use the turbulent motion to enhance their ability to move vertically, perhaps by detecting and responding to shear.

The uncertainty regarding the actual swimming speed does not cast doubt on the flux estimates. These were based on a model simplified for analytical tractability and therefore less than perfectly quantitative. Model assumptions included a logarithmic velocity distribution (a good fit except near slack water; Hinwood 
\& Jones 1979, Hinwood pers comm.), and an exponential copepod distribution. The latter gave a reasonable fit on most profiles. The variation of the actual profiles from the fitted curve results in error variance in the $\omega$ values, which in turn appears in the $Y^{\prime}$ values, and is taken into account. The assumptions used in the model of a rectilinear tide and instantaneous change of vertical distribution probably introduce a small amount of error. The copepods responded quickly to the onset and end of slack water (Fig. $2 \& 3$ ), and the errors resulting from these 2 assumptions cancel to some extent.

The mean value of $Y^{\prime}$ for Acartia tranteri (M) from the model was 1.18. Any value of the ratio $\left(Q_{2}+Q_{1}\right) /\left(Q_{2}-\right.$ $Q_{1}$ ) having $Q_{2}>Q_{1}$ would result in $Y$ exceeding 1 ; that is, in the vertical migration flux exceeding and opposing the mixing flux. Data from 9 sets of samples in Sectors 1 and 2 show that $Q_{2}>Q_{1}$ on all 9 dates, with a mean ratio of 1.35 (Kimmerer \& McKinnon 1987a). We assume that abundances in the east and northwest arms of the bay are similar, as they were on 3 occasions in 1982-3 (Kimmerer \& McKinnon 1985). Since Y exceeds 1 on the average (range 0.4 to 2.6 ), and differs significantly from 0 as shown above, we conclude that the vertical migration of $A$. tranteri $(M)$ is sufficiently large to prevent loss of adults from the bay through mixing.

The tidal migration pattern of total Acartia tranteri adults in Sample Set 1 resembled that of the medium size class, even though about half of the adults were of the larger size class, because the abundance pattern of the large size class was unrelated to tide. Copepodites were not identified to size class, but if the tidal migration pattern were present in copepodites of the medium size class it should have been evident in the data for total A. tranteri copepodites. The abundance pattern of the copepodites was completely different from those of the medium and large adults, with no significant tidal or diel effect. The samples included copepodites as small as Stage III, which are about $2 / 3$ the length of adults (Kimmerer \& McKinnon 1987a, b). If swimming speed is proportional to length, then the copepodites should still be physically capable of undergoing the tidal migration to the extent where it would have been detected. The absence of tidal migration in the copepodites of $A$. tranteri $(M)$ remains unexplained, although not clearly demonstrated.

No Bass Strait resident species showed significant variation of vertical position with tides in any sample set. The absence of tidal migration in these species is not likely to be due to insufficient swimming ability: Paracalanus indicus showed significant diel migration, and the other species are mostly larger than either $P$. indicus or Acartia tranteri (M). Also, Calanus australis and euphausiids are known to migrate vertically on a diel cycle in Bass Strait (Kimmerer \& McKinnon 1984).
The difference in migratory behavior between Acartia tranteri $(\mathrm{M})$ and Bass Strait residents probably arises from a difference in adaptive requirements. Species resident in the bay are constantly exposed to removal from the bay by mixing, which presumably causes a reduction in food concentration and in the probability of encounter with potential mates. Thus a selective advantage exists for a behavioral mechanism that minimizes washout. Individuals of neritic species would also benefit by being able to avoid mixing into the bay, since their populations are reduced there, probably by excess mortality (Kimmerer \& McKinnon 1987a). However, neritic populations occupy large areas not near bay entrances; only a minute fraction of the population is exposed to this risk, and the proportion of the whole population lost into the bay would be extremely small. Thus little selective pressure exists to offset the energy expenditure presumed necessary to undergo the migrations.

Among the bay resident species collected in Sample Set 1 , the only one besides Acartia tranteri (M) to show any sign of tidally induced migration was Pseudodiaptomus cornutus (adults). This species is demersal, undergoing diel migration with no evidence of a tidal effect, in a small tidal channel in the eastern arm of Westernport Bay (Fancett \& Kimmerer 1985). In the western entrance it did not migrate on a diel cycle. This difference suggests considerable behavioral plasticity in this species; other members of the genus exhibit a variety of diel and tidal migratory patterns (e. g. Wooldridge \& Frasmus 1980).

Of the remaining bay resident in Sample Set 1 , only Paracalanus crassirostris and Bestiola similis were very abundant. Both are closely related to $P$. indicus; $B$. similis is very similar to $P$. indicus in both size and appearance, and $P$. crassirostris is slightly smaller. Since $P$. indicus can evidently migrate dielly in the western entrance, the absence of migratory behavior in the 2 bay resident species is probably not due to an inability to sustain the necessary swimming speed. These species grow rapidly over a few months in the summer and then disappear; perhaps the small amount of mortality due to washout from the bay is more tolerable to these rapidly growing species than to the more slowly growing Acartia tranteri (M) (Kimmerer 1983 [B. similis as Acrocalanus inermis], Kimmerer \& McKinnon 1985, $1987 \mathrm{a}, \mathrm{b})$.

Acknowledgements. Funding was provided by Australian Marine Sciences and Technologies Grant 83/1325 R. We thank the students of the 1985 Ecology Honours Field Camp for assistance with sampling, J. Hinwood for helpful discussions, and I. A. E. Bayly and J. N. Kremer tor reviews of the manuscript. 


\section{LITERATURE CITED}

Alldredge, A. L., Hamner, W. M. (1980). Recurring aggregation of zooplankton by tidal currents. Estuar. coast. mar Sci. 10: 31-37

Bosch, H. F., Taylor, W. R. (1973). Diurnal vertical migration of an estuarine cladoceran podon polyphemoides in the Chesapeake Bay. Mar. Biol. 10: 172-181

Cronin, T. W. (1982). Estuarine retention of larvae of the crab Rhithropanopeus harrisiz. Estuar. coast. Shelf Sci. 15: $207-220$

Cronin, T. W., Forward, R. B., Jr. (1979). Tidal vertical migration: an endogenous rhythm in estuarine crab larvae. Science 205: 1020-1022

Enright, J. T. (1977). Copepods in a hurry: sustained highspeed upward migration. Limnol. Oceanogr. 22: 118-125

Fancett, M. S., Kimmerer, W. J. (1985). Vertical migration of the demersal copepod Pseudodiaptomus as a means of predator avoidance. J. exp. mar. Biol. Ecol. 88: 31-43

Greer Walker, M., Harden Jones, F. R., Arnold, G. P. (1978). The movements of plaice (Pleuronectes platessa L.) tracked in the open sea. J. Cons. int. Explor. Mer. 38: $58-86$

Hardy, A. C., Bainbridge, R. (1954). Experimental observations on the vertical migration of planktonic animals. J. mar. biol. Ass. U.K. 33: 409-448

Harris, J. E., Robinson, J. B. (1979). Circulation in Western Port, Victoria, as deduced from salinity and reactive-silica distributions. Mar. Geol. 30: 101-116

Hinwood, J. B., Jones, J. C. E. (1979). Hydrodynamic data for Western Port, Victoria. Mar. Geol. 30: 47-63

Jacobs, J. (1968). Animal behavior and water movement as codeterminants of plankton distribution in a tidal system. Sarsia 34: 355-570

Kimmerer, W. J. (1983). Direct measurement of the production: biomass ratio of the subtropical calanoid copepod Acrocalanus inermis. J. Plankton Res. 5: 1-14

Kimmerer, W. J., McKinnon, A. D. (1984). Zooplankton abundances in Bass Strait and westem Victoria shelf waters, March 1983. Proc. R. Soc. Vict. 96: 161-167

Kimmerer, W. J. McKinnon, A. D. (1985). A comparative study of the zooplankton in two adjacent embayments, Port Phillip and Westernport Bay, Australia. Estuar. coast. Shelf Sci. 21: 145-159

Kimmerer, W J., McKinnon, A. D. (1987a). Zooplankton in a marine bay. I. Horizontal distributions used to estimate net population growth rates. Mar. Ecol. Prog. Ser. 41: 43-52
Kimmerer, W. J., McKinnon, A. D. (1987b). Growth, mortality, and secondary production of the copepod Acartia tranter in Westemport Bay, Australia. Limnol. Oceanogr. 32 $14-28$

Landry, M. R. (1978). Population dynamics and production of a planktonic marine copepod, Acartia clausii, in a small temperate lagoon on San Juan Island, Washington. Int. Revue ges. Hydrobiol. 63: 77-119

Orsi, J. J. (1986). Interaction between diel vertical migration of a mysidacean shrimp and two-layered estuarine flow. Hydrobiologia (in press)

Osonphasop, C. (1983). The measurements of turbulence in tidal currents. Ph.D. thesis, Monash Univ., Victoria, Australia

Osonphasop, C., Hinwood, J. B. (1984). On measurement of turbulence and shear stresses in tidal currents. In: Proceedings 4 th Congress - Asian and Pacific Division, International Association for Hydraulic Research. Chiang Mai, Thailand. p. 339-353

Peterson, W. T., Miller, C. B., Hutchinson, A. (1979). Zonation and maintenance of copepod populations in the Oregon upwelling zone. Deep Sea Res. 26: $467-494$

Pritchard, D. W., Schubel, J. R. (1981). Physical and geological processes controlling nutrient levels in estuaries. In: Neilson, B. J., Cronin, L. E. (ed.) Estuaries and nutrients. Humana, Clifton, New York, p. 47-69

Rothlisberg, P. C., Church, J. W., Forbes, A. M. G. (1983). Modelling the advection of vertically migrating shrimp larvae. J. mar. Res. 41: 511-538

Seliger, H. H., Carpenter, J. H., Loftus, M., McElroy, W. D. (1970). Mechanisms for the accumulation of high concentrations of dinoflagellates in a bioluminescent bay. Limnol. Oceanogr. 15: 234-245

Stavn, R. H. (1971). The horizontal-vertical distribution hypothesis: Langmuir circulations and Daphnia distributions. Limnol. Oceanogr. 16: 453-466

Sulkin, S. D. (1984). Behavioral basis of depth regulation in the larvae of brachyuran crabs. Mar. Ecol. Prog. Ser. 15: $181-205$

Trinast, E. M. (1975). Tidal currents and Acartia distribution in Newport Bay, California. Estuar. coast. mar. Sci. 3: 165-176

Wooldridge, T., Erasmus, T. (1980). Utilization of tidal currents by estuarine zooplankton. Estuar. coast. mar. Sci. 11: $107-114$

Young, P. C., Carpenter, S. M. (1977). Recruitment of postlarval penaeid prawns to nursery areas in Moreton Bay, Queensland. Aust. J. mar. Freshwat. Res. 28: 745-773 